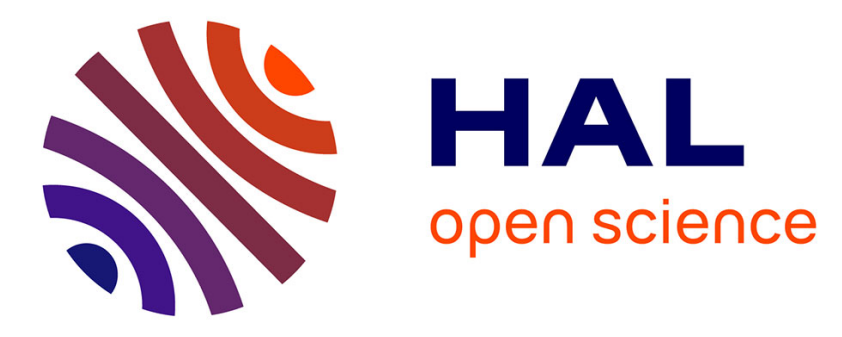

\title{
Influence of molecular length on the adsorption of linear trimethylsilylacetylene derivatives at the n-tetradecane/Au(111) interface: chemisorption vs. physisorption
}

Aymeric Nion, Nathalie Katsonis, Alexandre Marchenko, Corinne Aubert, Denis Fichou

\section{To cite this version:}

Aymeric Nion, Nathalie Katsonis, Alexandre Marchenko, Corinne Aubert, Denis Fichou. Influence of molecular length on the adsorption of linear trimethylsilylacetylene derivatives at the ntetradecane/ $\mathrm{Au}(111)$ interface: chemisorption vs. physisorption. New Journal of Chemistry, 2013, 37 (8), pp.2261-2265. 10.1039/c3nj00334e . hal-01397908

\author{
HAL Id: hal-01397908 \\ https://hal.science/hal-01397908
}

Submitted on 3 Sep 2021

HAL is a multi-disciplinary open access archive for the deposit and dissemination of scientific research documents, whether they are published or not. The documents may come from teaching and research institutions in France or abroad, or from public or private research centers.
L'archive ouverte pluridisciplinaire HAL, est destinée au dépôt et à la diffusion de documents scientifiques de niveau recherche, publiés ou non, émanant des établissements d'enseignement et de recherche français ou étrangers, des laboratoires publics ou privés. 


\title{
Influence of molecular length on the adsorption of linear trimethylsilylacetylene derivatives at the $n$-tetradecane/Au(111) interface: chemisorption vs. physisorption $\dagger$
}

\author{
Aymeric Nion, ${ }^{a}$ Nathalie Katsonis, ${ }^{b}$ Alexandre Marchenko, ${ }^{c}$ Corinne Aubert ${ }^{\mathrm{a}}$ and \\ Denis Fichou*a
}

\begin{abstract}
Adsorption of two trimethylsilylacetylene (TMSA) derivatives bearing linear alkyl chains of different lengths has been studied at the $n$-tetradecane/Au(111) interface. The lying or standing orientation of TMSA compounds on the gold surface shows that adsorption is not only controlled by the chemical reactivity of the molecules but also by their size.
\end{abstract}

The chemical grafting of organic molecules on metal surfaces is a versatile technique used to achieve surface functionalization. ${ }^{1-3}$ Such an attachment occurs via the formation of a covalent bond between the molecule and a metal atom and the growth of a selfassembled monolayer (SAM). The most widely investigated SAM compounds possess a sulfur-based anchoring group, such as thiols or sulphides for example, ${ }^{4,5}$ and are deposited on an atomically flat surface of $\mathrm{Au}(111)$. Over the last two decades this technique has been extensively investigated because it offers a variety of potential applications in fields as diverse as chemical sensing, ${ }^{6}$ corrosion inhibition, ${ }^{7}$ nanopatterning, ${ }^{8}$ catalysis, ${ }^{9}$ and microelectronics, ${ }^{10}$ to name a few. From a more fundamental point of view, SAMs are also important in surface science since they form a variety of 2D-lattices whose structure depends on deposition conditions and substrate surface..$^{5,11-16}$

However, organothiols possess a limited stability toward oxidation in air, ${ }^{17,18}$ which drastically limits their use in a number of applications. This long term instability has triggered a quest for novel sulfur-free anchoring groups allowing attachment on gold through various atoms such as silicon, ${ }^{19-21}$ selenium, ${ }^{22,23}$ tin, ${ }^{21}$ or even carbon. ${ }^{24-26}$ In particular, we discovered that

\footnotetext{
${ }^{a}$ UPMC Univ Paris 06, Institut Parisien de Chimie Moléculaire (IPCM), UMR 7201 CNRS, 4 place Jussieu, 75252 Paris Cedex, France. E-mail: denis.fichou@upmc.fr; Fax: +33 144277063; Tel: +33 144275080

${ }^{b}$ MESA+ Institute for Nanotechnology, University of Twente, P.O. Box 217, 7500 AE Enschede, The Netherlands

${ }^{c}$ Institute of Physics, National Academy of Sciences of Ukraine, Kyiv, Ukraine

$\dagger$ Dedicated to the memory of Dr Aymeric Nion.
}

trimethylsilylacetylene (TMSA) derivatives form long-range and highly stable SAMs at the $n$-tetradecane/Au(111) interface. $^{20}$ High-resolution scanning tunnelling microscopy (STM) shows that the TMSA motif $-\mathrm{C} \equiv \mathrm{C}-\mathrm{Si}\left(\mathrm{CH}_{3}\right)_{3}$ spontaneously adsorbs on gold in an upright position, the silicon atom being in direct contact with gold. A molecular approach revealed the key role played by the TMSA head in the self-assembly of a series of linear TMSA analogs. ${ }^{27}$ This study demonstrated that selfassembly arises primarily from the activation of the $\mathrm{Si}$ atom by the $\mathrm{C} \equiv \mathrm{C}$ triple bond of TMSA, thus inducing the creation of a surface complex through a local $\mathrm{Si}-\mathrm{Au}$ bond. Besides, a slight chemical modification of the TMSA group modifies the chemical reactivity versus $\mathrm{Au}(111)$ and hence the adsorption geometry. For example, STM and synchrotron radiation photoelectron spectroscopy clearly show that the replacement of a $\mathrm{CH}_{3}$ group by a $\mathrm{H}$ atom on the TMSA motif leads to SAMs with

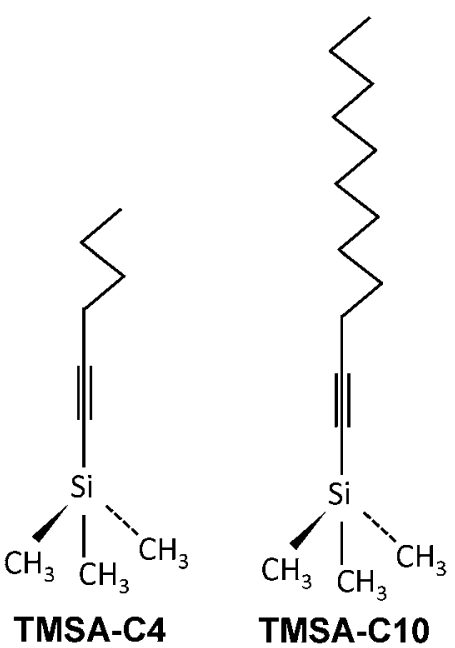

Scheme 1 Chemical structures of the two trimethylsilylacetylenes (TMSA) under study here. 
molecules lying horizontal on the substrate instead of standing upright. ${ }^{28}$ Note that very recently the TMSA moiety has been used as a molecule-gold contact, resulting in a simplified conductance profile of molecular junctions. ${ }^{29}$

If the anchoring process of the TMSA group on gold is fairly well understood, the role of the molecular structure bearing the TMSA group in the SAM growth mechanism remains unclear. Its size, shape and chemical nature may determine the positioning of individual molecules in the overlayer and induce various phases. We report here on a comparative study of two TMSA derivatives bearing linear alkyl chains of different lengths, namely 1-trimethylsilyl-1-hexyne (TMSA-C4) and 1-trimethylsilyl1-dodecyne (TMSA-C10) (Scheme 1). For both compounds we investigate the formation of SAMs at the $n$-tetradecane/Au(111) interface using STM. The short chain TMSA-C4 readily forms large domains of a lamellar phase where molecules are lying flat on the substrate and parallel to each other. In contrast, the longer TMSA-C10 initially forms small domains of a short-range lamellar phase which rapidly evolves toward a compact hexagonal phase with molecules standing upright on $\mathrm{Au}(111)$ in a superstructure corresponding to a $(\sqrt{ } 3 \times \sqrt{ } 3) \mathrm{R} 30^{\circ}$ packing phase.

\section{TMSA-C4}

One hour after deposition of TMSA-C4 at the $n$-tetradecane/ $\mathrm{Au}(111)$ interface we observed the formation of large organized domains covering the gold terraces (Fig. 1a) entirely. These domains possess a lamellar structure with parallel lamellae growing preferentially along the $\langle 112\rangle$ direction of gold and can be oriented at $120^{\circ}$ respective to each other, thus reflecting the symmetry of the $\mathrm{Au}(111)$ substrate. In contrast to reported observations with a series of longer TMSA derivatives, ${ }^{20,27}$ no evidence of chemical degradation of the gold surface is observed (etch-pits, irregular step edges, etc.). Furthermore, neither longer immersion times nor higher concentrations of TMSA-C4 in the transfer medium modify this arrangement. It shows that TMSA-C4 is not chemisorbed on gold but rather simply physisorbed through weak van der Waals interactions.

At higher resolution the STM images reveal that in the same domain the neighbouring lamellae are not always equidistant. This is clearly visible on the profile lines shown in Fig. $1 \mathrm{~b}$ and $\mathrm{c}$ where consecutive peaks are separated by either $25 \pm 2 \AA$ or $14 \pm 2 \AA$ (see blue circles). We assume that the bright lines in the STM images correspond to the bulky $\mathrm{Si}\left(\mathrm{CH}_{3}\right)_{3}$ motifs while the darker areas correspond to the $-\mathrm{C} \equiv \mathrm{C}_{-} \mathrm{C}_{4} \mathrm{H}_{9}$ chains. We also observe on the profile line shown in Fig. $1 \mathrm{~b}$ that each peak has two components, with a shoulder of weaker intensity on the left side of the main peak. Finally, Fig. 1d reveals that individual TMSA-C4 molecules constitutive of the lamellae are stacked parallel to each other. These images first show that the TMSA-C4 molecules are lying flat on the gold substrate, in a head-to-head and hence a tail-to-tail fashion from one lamella to the next with an average inter-lamellar distance of $25 \pm 2 \AA$. However, this arrangement coexists with lamellae positioned head-to-tail and separated by a distance of only $14 \pm 2 \AA$. This local head-to-tail arrangement is indicated by white arrows in a)

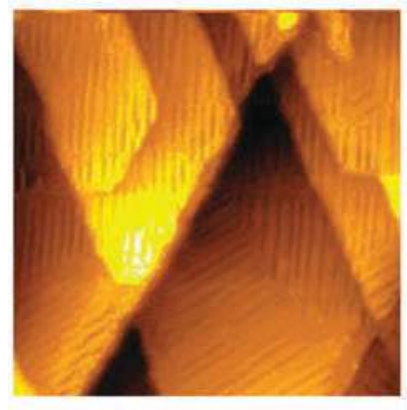

c)

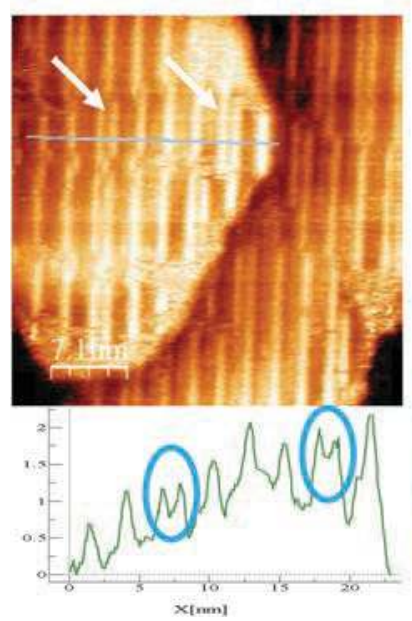

b)

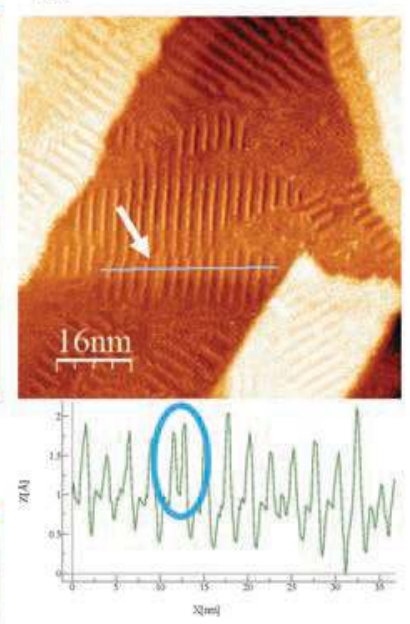

d)

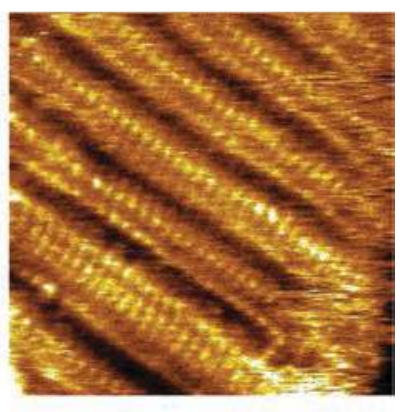

Fig. 1 STM images of the TMSA-C4 lamellar phase at the $n$-tetradecane/Au(111) interface recorded two hours after deposition. (a) $100 \times 100 \mathrm{~nm}^{2} ; U_{\mathrm{t}}=471 \mathrm{mV} ; I_{\mathrm{t}}=$ $754 \mathrm{pA}$. (b) $80 \times 80 \mathrm{~nm}^{2} ; U_{\mathrm{t}}=150 \mathrm{mV} ; I_{\mathrm{t}}=129 \mathrm{pA}$. (c) $35 \times 35 \mathrm{~nm}^{2} ; U_{\mathrm{t}}=150 \mathrm{mV} ; l_{\mathrm{t}}=$ $370 \mathrm{pA}$. (d) $16 \times 16 \mathrm{~nm}^{2} ; U_{\mathrm{t}}=150 \mathrm{mV} ; I_{\mathrm{t}}=129 \mathrm{pA}$. Profiles are recorded along the blue lines. White arrows and blue ovals indicate head-to-tail lamellae.

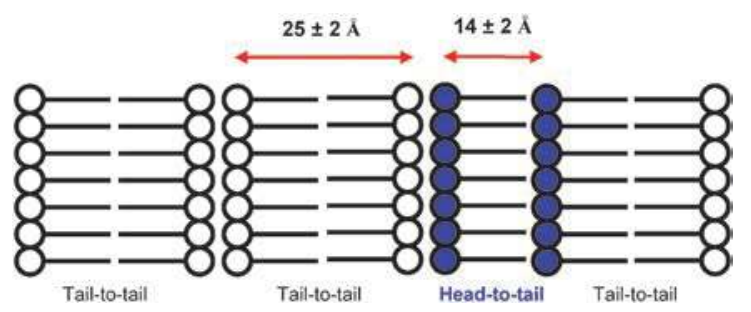

Scheme 2 Proposed packing model for TMSA-C4 molecules lying flat on $\mathrm{Au}(111)$ and combining lamellae in a head-to-head and head-to-tail arrangements. Circles represent the $\mathrm{Si}\left(\mathrm{CH}_{3}\right)_{3}$ motifs (heads) and the straight lines stand for the $-\mathrm{C} \equiv \mathrm{C}-\mathrm{C}_{4} \mathrm{H}_{9}$ chains (tails).

Fig. $1 \mathrm{~b}$ and c. A model of this arrangement is proposed in Scheme 2.

\section{TMSA-C10}

Fig. 2a shows a typical large scale STM image of the longer TMSA-C10 deposited on bare $\mathrm{Au}(111)$ recorded one hour after deposition. Gold terraces are covered with depressions having diameters in the range $3-10 \mathrm{~nm}$ and an average depth of 
a)

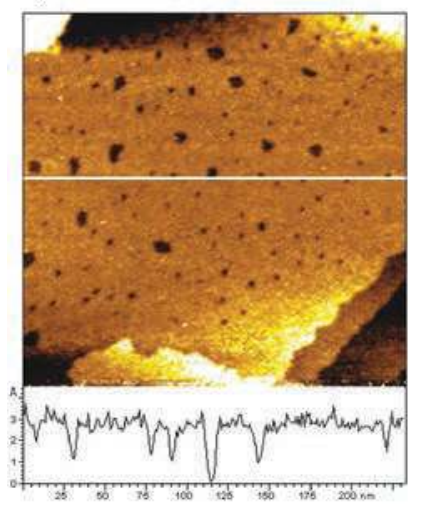

c)

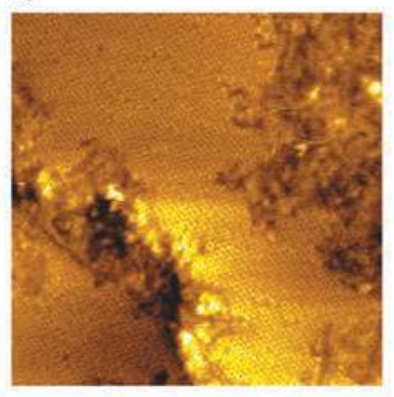

b)

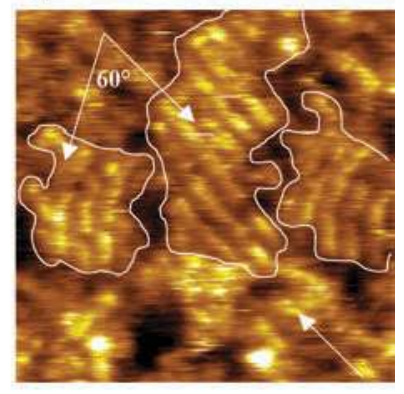

d)

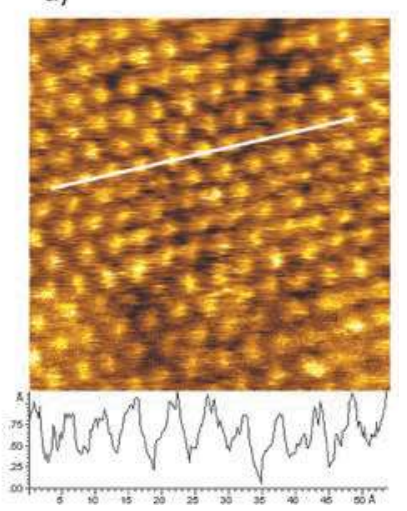

Fig. 2 Typical constant current STM images of TMSA-C10 deposited on Au(111) recorded one hour ( $a$ and $b$ ) and three hours ( $c$ and $d$ ) after deposition. The height profiles are recorded along the horizontal white lines. (a) $232 \times 232 \mathrm{~nm}^{2}$; $U_{\mathrm{t}}=600 \mathrm{mV} ; I_{\mathrm{t}}=18 \mathrm{pA}$. (b) $28 \times 28 \mathrm{~nm}^{2} ; U_{\mathrm{t}}=673 \mathrm{mV} ; I_{\mathrm{t}}=21 \mathrm{pA}$. Small organized lamellar domains oriented at $60^{\circ}$ are delimited by white lines. (c) $37 \times 37 \mathrm{~nm}^{2}$; $U_{\mathrm{t}}=604 \mathrm{mV}, I_{\mathrm{t}}=13 \mathrm{pA}$. (d) $6.3 \times 6.3 \mathrm{~nm}^{2} ; U_{\mathrm{t}}=604 \mathrm{mV}, I_{\mathrm{t}}=13 \mathrm{pA}$. In (d), the bright spots represent individual upright standing molecules in a hexagonal $(\sqrt{3} \times \sqrt{3})$ R30 $0^{\circ}$ packing phase.

$\sim 2.4 \AA$ corresponding to the van der Waals diameter of a gold atom, as seen in the cross-sectional height profile taken along the white line in Fig. 2a. We identify these depressions as regions where gold atoms are missing in the first layer of the gold surface. The apparent depth of the smaller pits with diameter $<2 \mathrm{~nm}$ is less than $\sim 2.4 \AA$ because of the scanning conditions (scan rate, tip shape, etc.). These etch-pits are typical of the $n$-alkanethiol adlayers chemisorbed on $\mathrm{Au}(111)$. Degradation of Au step edges is clearly visible (bottom right corner) and confirms the chemical reactivity of the TMSA moiety with the Au surface. At a higher resolution, we also observe that the gold surface is partially covered by small domains of a lamellar phase located in-between the pits (Fig. 2b). Different domains oriented at $60^{\circ}$ corresponding to the $\mathrm{Au}(111)$ substrate symmetry are visible. The corrugation period within the domains is $\sim 18 \AA$, which corresponds to the length of the TMSA-C10 molecule, thus confirming that molecules are lying flat on gold. In contrast to the well-organized TMSA-C4 lamellar phase, these domains only extend over a few nanometres.

For longer immersion times, typically three hours and more, a drastic modification of the surface morphology appears

progressively with the growth of highly ordered islands and the complete disappearance of the initial lamellae (Fig. 2c). Fig. 2d shows a high-resolution image recorded on top of one of these islands. The data show bright protrusions that can be assigned to individual TMSA-C10 molecules standing upright on the surface and forming a regular hexagonal arrangement corresponding to a $(\sqrt{ } 3 \times \sqrt{ } 3)$ R30 $0^{\circ}$ packing phase. The dimensions of the unit cell $(a=b=5.0 \pm 0.5 \AA)$ were determined from the height profiles recorded in the STM images. The $\mathrm{Si}\left(\mathrm{CH}_{3}\right)_{3}$ heads of TMSA-C10 are commensurate with the underlying $\mathrm{Au}(111)$ lattice along the $\langle 112\rangle$ direction, as observed with other linear TMSA compounds. ${ }^{20}$ The lying-to-standing phase transition of TMSA-C10 at the $n$-tetradecane/Au(111) interface results from a non-equilibrium between weak and strong interactions. The lying lamellar phase is essentially governed by molecule-molecule interactions of van der Waals type (chain-chain interactions, etc.) while the standing phase arises from a slow chemical reaction between the Si atom and gold. In the latter case, the reaction proceeds via the formation of a local surface complex between the TMSA moiety and gold. Upon activation by the electron-withdrawing $\mathrm{C} \equiv \mathrm{C}$ bond, the Si-atom becomes pentacoordinated and adopts a bipyramidal geometry when in contact with an electron-donating atom such as Au. ${ }^{26,27}$ Such a hypothesis has been reinforced by means of synchrotron radiation induced photoelectron spectroscopy (SR-PES). ${ }^{28}$

The difference in length between TMSA-C4 and TMSA-C10 cannot account for a difference in the reactivity of the Si atom. However it can induce different mobilities of both molecules in the solvent and on the gold surface. Besides, in order to react with gold the linear and rigid $-\mathrm{C} \equiv \mathrm{C}-\mathrm{Si}\left(\mathrm{CH}_{3}\right)_{3}$ moiety needs to be positioned vertically relative to the surface. Then, the shorter TMSA-C4 will rapidly immobilize on the surface and form highly stable lamellae with the TMSA head oriented parallel to the surface, thus preventing any chemisorption. In contrast the long flexible chains of TMSA-C10 will induce variable positions of the $-\mathrm{C} \equiv \mathrm{C}-\mathrm{Si}\left(\mathrm{CH}_{3}\right)_{3}$ moiety relative to the $\mathrm{Au}$ atom. Even if an initial lamellar phase is formed this mobility will progressively lead the TMSA-C10 molecules to a vertical position so that the $\mathrm{Si}$ atom can react with gold. Note that a similar "lying vs. standing" competition has already been observed with alkylammonium compounds of different lengths adsorbed on layered silicates. ${ }^{30}$ However in the latter case the phenomenon was not related to chemisorption and physisorption.

In summary, STM at the $n$-tetradecane/Au(111) interface under ambient conditions reveals that the adsorption process of linear aliphatic TMSA compounds is highly dependent on the molecular length. Similar to other TMSA derivatives reported in the literature so far, the long chain TMSA-C10 is chemically linked to gold via a $\mathrm{Si}-\mathrm{Au}$ bond and forms SAMs with molecules standing upright in a hexagonal closepacked arrangement. In contrast, the short chain TMSA-C4 self-assembles into a stable lamellar phase with molecules lying flat on the surface through weak van der Waals interactions. This unexpected "lying vs. standing" orientation of TMSA compounds on the gold surface clearly shows that the 
"physisorption vs. chemisorption" competition is not only controlled by the chemical reactivity of the molecules but also by their size.

\section{Experimental section}

\section{Synthetic procedure}

Reactions were carried out under argon. Diethyl ether and THF were distilled from sodium-benzophenone under nitrogen before use. Dichloromethane was dried and distilled from $\mathrm{CaH}_{2}$. Merck Geduran SI60A silica gel $(35-70 \mu \mathrm{m})$ was used for column chromatography; PE and EE refer to petroleum ether and diethyl ether, respectively. NMR spectra were recorded using a $400 \mathrm{MHz}$ ARX400 Bruker spectrometer; chemical shifts are given in ppm, referenced to the residual proton resonances of the solvent $\left(\delta=7.26 \mathrm{ppm}\right.$ for $\left.\mathrm{CDCl}_{3}\right)$. Coupling constants $(J)$ are given in Hertz $(\mathrm{Hz})$. The terms $\mathrm{m}, \mathrm{s}$, brs, d, t, q, and quint refer to multiplet, singlet, broad singlet, doublet, triplet, quadruplet and quintuplet respectively. All reactions were performed according to the following general procedure: dilution with $\mathrm{Et}_{2} \mathrm{O}$, washing with a saturated solution of $\mathrm{NH}_{4} \mathrm{Cl}$ and brine dried over $\mathrm{MgSO}_{4}$, filtered, and concentrated in vacuum.

Synthesis of 1-trimethylsilyl-1-hexyne (TMSA-C4). To a solution of $5.74 \mathrm{~mL}$ ( $50 \mathrm{mmol}$ ) of 1-hexyne in $25 \mathrm{~mL}$ of THF at $-78{ }^{\circ} \mathrm{C} 2.1 \mathrm{~mL}$ of butyl lithium (2.5 M) (52.5 mmol, 1.05 eq.) in $\mathrm{THF}$ were added. The mixture was allowed to stir for 20 minutes at $-78{ }^{\circ} \mathrm{C}$ and then for 1 hour at $0{ }^{\circ} \mathrm{C}$. The solution was cooled down to $-78{ }^{\circ} \mathrm{C}$ and $6.48 \mathrm{~mL}$ (52.5 mmol, 1.05 eq.) of trimethylsilylchloride were added. The mixture was allowed to warm to ambient temperature and then stirred for an additional 2 hours. The addition of $50 \mathrm{~mL}$ of water and $50 \mathrm{~mL}$ of ether followed by drying of the organic layer over sodium sulphate, removal of the solvent, and purification of the residue using column chromatography (with petroleum ether) gave $7.29 \mathrm{~g}(96 \%)$ of the product isolated as a colourless oil. ${ }^{1} \mathrm{H}$ NMR (400 MHz, $\left.\mathrm{CDCl}_{3}\right): \delta 0.181(9 \mathrm{H}, \mathrm{s}), 0.89(3 \mathrm{H}, \mathrm{t}, J=$ $6.8 \mathrm{~Hz}), 1.34-1.45(4 \mathrm{H}, \mathrm{m}), 2.18(2 \mathrm{H}, \mathrm{t}, J=6.6 \mathrm{~Hz}) .{ }^{13} \mathrm{C} \mathrm{NMR}$ $\left(400 \mathrm{MHz}, \mathrm{CDCl}_{3}\right): \delta 0.18,13.12,19.86,21.60,30.9,81.21,108.13$.

Synthesis of 1-trimethylsilyl-1-dodecyne (TMSA-C10). To a solution of $1.08 \mathrm{~g}$ ( $6.49 \mathrm{mmol})$ of 1-dodecyne in $25 \mathrm{~mL}$ of THF at $-78{ }^{\circ} \mathrm{C} 2.8 \mathrm{~mL}$ of $2.25 \mathrm{M}(6.3 \mathrm{mmol})$ butyl lithium was added over $10 \mathrm{~min}$. The mixture was allowed to stir for 20 minutes and then for 1 hour at $0{ }^{\circ} \mathrm{C}$. The solution was cooled down to $-78{ }^{\circ} \mathrm{C}$ and $0.85 \mathrm{~mL}$ ( $6.65 \mathrm{mmol})$ of trimethylsilylchloride was added. The mixture was allowed to warm to ambient temperature and then stirred for 2 hours. The addition of $50 \mathrm{~mL}$ of water and $50 \mathrm{~mL}$ of ether followed by drying of the organic layer over sodium sulfate, removal of the solvent, and purification of the residue using column chromatography (with petroleum ether) gave $1.4 \mathrm{~g}(95 \%)$ of the product isolated as a colorless oil. ${ }^{1} \mathrm{H} \mathrm{NMR}\left(400 \mathrm{MHz}, \mathrm{CDCl}_{3}\right): \delta 0.176(\mathrm{~s}, 9 \mathrm{H}), 0.87(\mathrm{t}, J=6.82 \mathrm{~Hz}$, $3 \mathrm{H}$ ), $1.25(\mathrm{~m}, 12 \mathrm{H}), 1.35$ (quint, $J=6.63 \mathrm{~Hz}, 2 \mathrm{H}$ ), 1.50 (quint, $J=7.07 \mathrm{~Hz}, 2 \mathrm{H}), 2.20(\mathrm{t}, J=7.2 \mathrm{~Hz}, 2 \mathrm{H}) .{ }^{13} \mathrm{C} \mathrm{NMR}(400 \mathrm{MHz}$, $\left.\mathrm{CDCl}_{3}\right): \delta 0.18,14.12,19.86,22.69,28.64,28.80,29.09,29.33$, 29.51, 29.56, 84.20, 107.79 .
Scanning tunnelling microscopy. Gold substrates were prepared from gold films (thickness $\sim 150 \mathrm{~nm}$ ) deposited under ultrahigh vacuum $(\sim 5.10-8 \mathrm{~Pa})$ onto a freshly cleaved mica surface heated at $\sim 600 \mathrm{~K}$. Reconstruction of the $\mathrm{Au}(111)$ surface was ensured by a careful annealing of the gold films in a gas flame (propane-air) and checked using STM before sample deposition. A small quantity of the organic compound $\left(\sim 0.05 \mathrm{mg} \mathrm{ml}^{-1}\right)$ was then mixed in $n$-tetradecane $(99+\%$ purity, Aldrich), and a droplet of this solution was deposited onto the $\mathrm{Au}(111)$ substrate. STM images were recorded in $n$-tetradecane at room temperature by using a Pico-SPM (Agilent Technologies, Molecular Imaging). The STM tip was a Pt/Ir (80/20) wire sharpened by mechanical cutting. The experimental error in the measured lateral distances was within 5\%. The STM images recorded in the constant-current mode were obtained with different samples and conditions to test for reproducibility and ensure that the results were free of tip and sample artefacts. All STM images were flattened by the WSxM software. ${ }^{31}$

\section{Notes and references}

1 A. Ulman, Introduction to Ultrathin Organic Films: from Langmuir Blodgett to Self-Assembly, Academic Press, San Diego, CA, 1991.

2 A. Kumar and G. M. Whitesides, Science, 1994, 263, 60.

3 A. Ulman, Chem. Rev., 1996, 96, 1533.

4 R. G. Nuzzo and D. L. Allara, J. Am. Chem. Soc., 1983, 105, 4481.

5 G. E. Poirier, Chem. Rev., 1997, 97, 1117.

6 J. K. Schoer and R. M. Crooks, Langmuir, 1997, 13, 2323.

7 J. W. Zhao and K. Uosaki, Nano Lett., 2002, 2, 137.

8 J. C. Love, L. A. Estroff, J. K. Kriebel, R. G. Nuzzo and G. M. Whitesides, Chem. Rev., 2005, 105, 1103.

9 G. A. Samorjai, Surface Chemistry and Catalysis, Wiley-Interscience, New York, 1994.

$10 \mathrm{~J}$. Collet, O. Tharaud, A. Chapoton and D. Vuillaume, Appl. Phys. Lett., 2000, 76, 1941.

11 A. A. Dhirani, R. W. Zehner, R. P. Hsung, P. Guyot-Sionnest and L. R. Sita, J. Am. Chem. Soc., 1996, 118, 3319.

12 P. Jiang, A. Nion, A. Marchenko, L. Piot and D. Fichou, J. Am. Chem. Soc., 2006, 128, 12390.

13 L. Piot, C. Marie, X. Dou, X. Feng, K. Müllen and D. Fichou, J. Am. Chem. Soc., 2009, 131, 1378.

14 D. E. Hooks, T. Fritz and M. D. Ward, Adv. Mater., 2001, 13, 227.

15 A. Nion, P. Jiang, A. Popoff and D. Fichou, J. Am. Chem. Soc., 2007, 129, 2450.

16 P. Jiang, K. Deng, D. Fichou, S. S. Xie, A. Nion and C. Wang, Langmuir, 2009, 25, 5012.

17 T. M. Willey, A. L. Vance, T. Van Buuren, C. Bostedt, L. J. Terminello and C. S. Fadley, Surf. Sci., 2005, 576, 188.

18 Y. Joseph, B. Guse and G. Nelles, Chem. Mater., 2009, 21, 1670.

19 T. M. Owens, K. T. Nicholson, M. M. B. Holl and S. Suezer, J. Am. Chem. Soc., 2002, 124, 6800. 
20 A. Marchenko, N. Katsonis, D. Fichou, C. Aubert and M. Malacria, J. Am. Chem. Soc., 2002, 124, 9998.

21 D. Khobragade, E. S. Stensrud, M. Mucha, J. R. Smith, R. Pohl, I. Stibor and J. Michl, Langmuir, 2010, 26, 8483.

22 J. D. Monnell, J. J. Stapleton, J. J. Jackiw, T. Dunbar, W. A. Reinerth, S. M. Dirk, J. M. Tour, D. L. Allara and P. S. Weiss, J. Phys. Chem. B, 2004, 108, 9834.

23 A. Shaporenko, A. Ulman, A. Terfort and M. Zharnikov, J. Phys. Chem. B, 2005, 109, 3898.

24 J. J. Stapleton, T. A. Daniel, S. Uppili, O. M. Cabarcos, J. Naciri, R. Shashidhar and D. L. Allara, Langmuir, 2005, 21, 11061.

25 S. Zhang, K. L. Chandra and C. B. Gorman, J. Am. Chem. Soc., 2007, 129, 4876.

26 D. M. Shewchuk and M. T. McDermott, Langmuir, 2009, 25, 4556.
27 N. Katsonis, A. Marchenko, S. Taillemite, D. Fichou, D. Chouraqui, C. Aubert and M. Malacria, Chem.-Eur. J., 2003, 9, 2574.

28 N. Katsonis, A. Marchenko, D. Fichou and N. Barrett, Surf. Sci., 2008, 602, 9.

29 S. Marqués-González, D. S. Yufit, J. A. K. Howard, S. Martín, H. M. Osorio, V. M. García-Suárez, R. J. Nichols, S. J. Higgins, P. Ceac and P. J. Low, Dalton Trans., 2013, $42,338$.

30 L. A. Utracki, Clay-Containing Polymer Nanocomposites, Rapra, UK, 2004.

31 I. Horcas, R. Fernandez, J. M. Gomez-Rodriguez, J. Colchero, J. Gomez-Herrero and A. M. Baro, Rev. Sci. Instrum., 2007, 78, 013705. 